\title{
CALIBRATION OF DISTRIBUTED SHALLOW LANDSLIDE MODELS IN FORESTED LANDSCAPES
}

\author{
Gian Battista Bischetti, Enrico Antonio Chiaradia
}

\section{Introduction}

In mountainous-forested, soil mantled landscapes all around the world, rainfall-induced shallow landslides are one of the most common hydro-geomorphic hazards [Sidle 1985]. Such hazards frequently impact the environment and human lives and properties. In order to manage and protect human interests, landslide susceptibility maps must be produced [Guzzetti 1999] and several models have been proposed in the last decade [Montgomery 1998; Borga 2002; Casadei 2003; Claessens 2007; Talebi 2008; Kuriakose 2009].

The most common approach to shallow landslide modelling combines, in a GIS framework, simplified steady state topography-based hydrological models with the infinite slope scheme [Dietrich 1993; Montgomery 1994; Wu 1995; Pack 1998; Dietrich 1998; Borga 2002; van Beek 2002; Simoni 2008]. The success of such an approach is due to the simplicity of the steady-state hydrologic approach and the power of GIS technology in managing elevation and spatially distributed data. Although several issues affect the modelling results, the approach has been proven to be very useful and many Authors adopted it [e.g. Dietrich 1998; Wu 1995; Borga 2002; Montgomery 1994; Duan 2000; Pack 1998, 2005].

Among the open issues that still affect such an approach, the main ones are: i) the effect of the algorithm adopted to identify flow directions and contributing area [Huang 2007; Santini 2009], ii) the effect of DEM resolution and accuracy [Claessens 2005], iii) the effect of a steady state or dynamic approach to water pore pressure within the soil [Borga 2002; Rosso 2006], iv) the role of vegetation in soil resistance estimation [Kuriakose 2009], v) the evaluation of the model's performance [Huang 2007].

In the present paper we focus on the last two

Paper received 04.12.2009; accepted 25.05.2010

G.B. Bischetti, Professore Associato, E.A. Chiaradia, Assegnista di Ricerca, Dipartimento di Ingegneria Agraria - Università degli Studi di Milano, Via Celoria 2-20133 Milano, bischetti@unimi.it points, applying a spatially distributed model for slope stability estimation, the "Stability INdex MAPping - SINMAP" [Pack 1998, 2005], to a small forested pre-Alpine catchment, adopting different calibration approaches.

\section{Material and methods}

\subsection{The assessment of shallow slope stability model results}

According to Borga [2002] two types of errors can be identified in modelling slope instabilities: (1) a site is identified by the model as unstable, but no evidence of instability can be observed, (2) a site is predicted as stable, but instabilities have been observed.

The first type of error indicates that the model tends to over-predict areas potentially subject to shallow landsliding, whereas the second indicates that the model does not adequately describe the processes that caused the instability process.

In principle the first type of error could not be a true error because the predicted unstable condition should be viewed as an indication of a proneness to instability; it has not still occurred but it can manifest in the future, especially in very steep areas. The second type of error could have serious consequences when the considered model is applied to hazard mapping and it must be minimized.

To evaluate the performance of stability models, it is common to use the so-called Success Rate $(S R)$ [Montgomery 1994; Borga 2002; Duan 2000]. It is the ratio between the number of observed landslides actually occurred in predicted unstable areas $\left(N U_{R}\right)$ over the total number of observed landslides $\left(N U_{O}\right)$ :

$$
S R=N U_{R} N U_{O}
$$

$S R$ does not consider stable areas, where prediction can be correct or not.

Generally, it has been recognized that adopting $S R$ as a performance indicator, slope failure is over-predicted [Borga 2002; Casadei 2003; Huang and Kao]; as an extreme case, for example, if the whole area is classified as unstable, the resulting $S R$ will be $100 \%$. 
Huang [2006] and Rosso [2006], recently proposed more complex indexes.

Huang [2006] considered also the successfully predicted stable areas developing a Modified Success Rate, which is an average between the success in predicting unstable and stable areas:

$$
M S R=0.5 S R+0.5 \frac{S_{R}}{S_{o}}
$$

where $S_{R}$ are the successfully predicted stable cells and $S_{O}$ are the total number of actual stable cells.

Rosso [2006] considered a combinations of four sub-indexes:

$$
I_{a v}=\operatorname{average}\left(U_{R} / U_{O}, U_{R} / U_{c}, S_{R} / S_{O}, S_{R} / S_{C}\right)
$$

where: $U_{O}$ is the number of observed unstable cells, $U_{C}$ is the number of simulated unstable cells, $U_{R}$ is the number of rightly simulated unstable cells, $S_{C}$ is the number of simulated stable cells.

$U_{R} / U_{O}$ is an indicator of the model efficiency to identify landslides, $U_{R} / U_{c}$ can be viewed as an indicator of the manifested instability over the potential instability, $S_{R} / S_{O}$ is an indicator of the model efficiency to identify stable areas, $S_{R} / S_{C}$ is the reciprocal of $U_{R} / U_{c}$.

In the case of small instabilities, which have an extension of the order of one or a few hundreds of square meters [Dietrich 2007; Deb 2009], it can be assumed that each observed landside occupies one cell in a $10 \mathrm{~m}$ or $15 \mathrm{~m}$ grid size. The number of observed landslides that actually occurred in predicted unstable areas, then, can be approximated to the rightly simulated unstable cells and the total number of observed landslides can be approximated to the observed unstable cells:

and

$$
N U_{R}=U_{R} \quad N U_{O}=U_{O}
$$

$$
S R=U_{R} / U_{O}
$$

The index proposed by Huang [2006] (MSR), as a consequence, results in the average between the first and the third of the sub-indexes of Rosso [2006]:

$$
M S R=0.5\left(U_{R} / U_{O}+S_{R} / S_{O}\right)
$$

Recalling the two types of errors that may occur in slope stability modelling:

- high values of $S R$ (and $U_{R} / U_{O}$ ) indicate that the model may fail, falling in the first type of error (sites are identified by the model as unstable, but no evidence of instability can be observed) and low values that the model may fail falling in the second type of error (sites are predicted as stable, but instabilities have been observed);

- $U_{R} / U_{c}$ and $S_{R} / S_{C}$ do not give any real indication concerning the model performance;

- high values of $S_{R} / S_{O}$ indicates that the model is prone to fail, falling in the second type of error and low values that the model is prone to fail, falling in the first type of error.

The combination of $S R$ and $S_{R} / S_{O}$ as proposed by
Huang [2006], then, represents the best way to evaluate stability model performance.

Due to the fact that it is more difficult to predict actual unstable areas (see the first type of errors as reported at the top [Carrara 1995; Borga, 2002]) we think that the two indexes should not have the same weight, as in the case of MSR, but SR should prevail.

Based on such consideration, we introduce a weighted average index (WMSR) that gives an arbitrarily weight of $2 / 3$ to $S R$ and a weight of $1 / 3$ to $S_{R} / S_{O}$.

\subsection{SINMAP}

Among the different models that have been proposed in the last years in the field of rainfall-triggered shallow landslides, the most widely applied are SHALSTAB [Dietrich 1998] and SINMAP (Stability INdex MAPping) [Pack 1998], which are freely distributed.

Such models couple the infinite slope stability model and the assumption of hydrologic steady state to compute pore water pressure in the soil.

In the present work, the SINMAP model was preferred to SHALSTAB due to its capability to manage slope stability from a probabilistic perspective [Meisina 2007]. SINMAP has also been tested in different landscapes and conditions [Morrissey 2001; Zaitchik 2003; Calcaterra 2004; Lan 2004; Meisina 2007].

The original version of the model is distributed under a GNU General Public Licence version as an extension of a commercial GIS software; in the present work we used a version re-built for the open-source software MapWindow [Chiaradia 2009].

In the infinite slope stability approach, the Factor of Safety $(F S)$ is [Hammond 1992]:

$$
F S=\frac{c_{,}+c_{r}+\left(\gamma_{s} D-\gamma_{n} D_{n}\right) \cos ^{2} \beta \operatorname{tg} \phi}{\gamma_{n} \cdot D \cdot \sin \beta \cdot \cos \beta}
$$

where (fig. 1) $c_{s}$ is the soil cohesion $(\mathrm{kPa}), c_{r}$ is the additional root cohesion $(\mathrm{kPa}), \gamma_{s}$ is the soil unit weight $\left(\mathrm{kN} / \mathrm{m}^{3}\right), \gamma_{w}$ is the water unit weight $\left(\mathrm{kN} / \mathrm{m}^{3}\right)$, $D$ is the vertical soil depth (m), $D_{w}$ is the vertical water depth (m), $\beta$ is slope angle $\left(^{\circ}\right)$ and $\phi$ is the internal friction angle $\left(^{\circ}\right)$

Introducing the variables:

$$
C=\frac{c_{s}+c_{r}}{h_{\gamma_{s}}} \quad(-r), r=\frac{\gamma_{w}}{\gamma_{s}} \quad(-), w=\frac{\nu_{k}}{D}=\frac{n_{k}}{h}
$$

where $h=D \cos \beta$ is soil thickness equation (5) can be rewritten and $F S$ can be expressed as:

$$
F S=\frac{C+\cos \beta(1-w r) \operatorname{tg} \phi}{\sin \beta}
$$

Adopting a modified version of the TOPMODEL approach [Beven 1979] the relative wetness $(w)$ can be evaluated as:

$$
w=\min \left(\frac{R a}{T \sin \beta}, 1\right)
$$




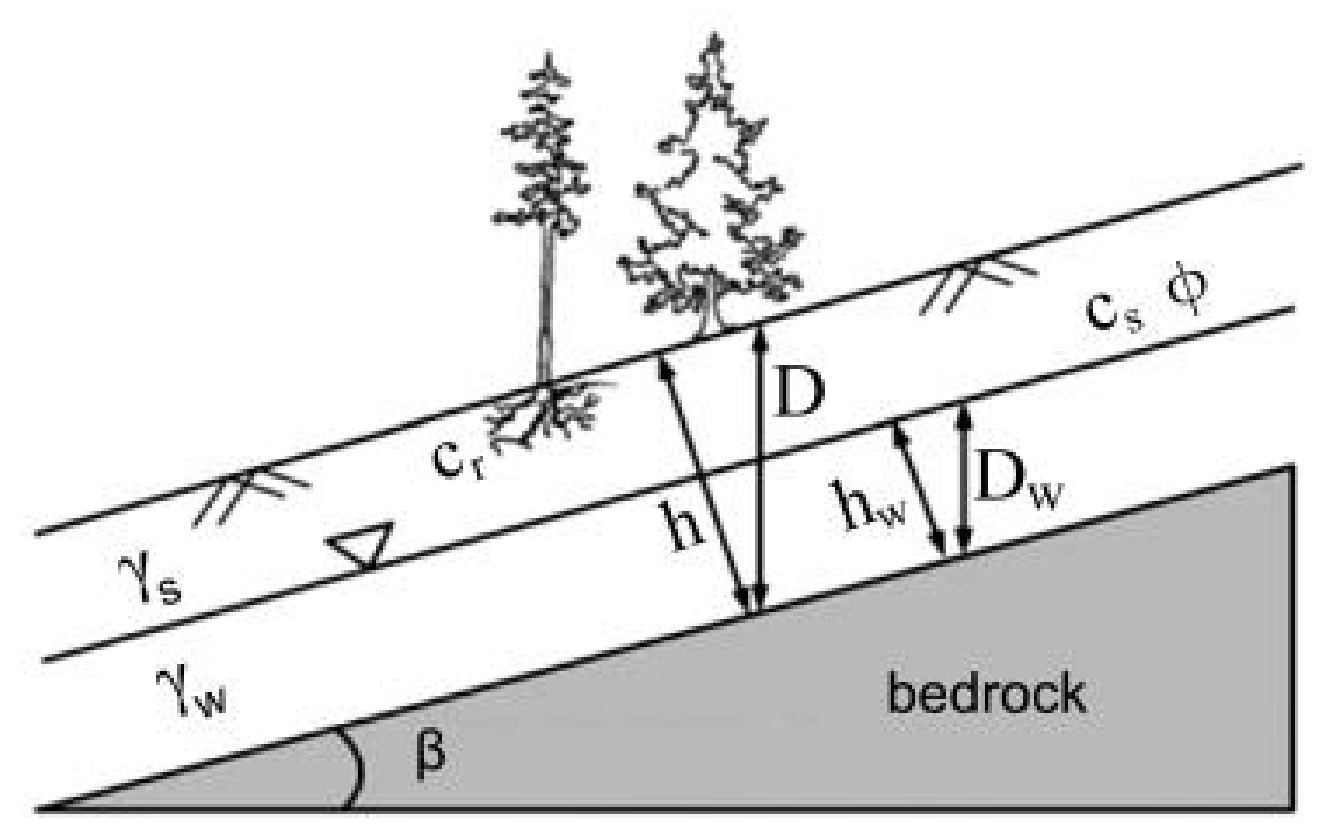

Fig. 1 - infinite slope stability scheme (after Hammond [2009])

where $T$ is the transmissivity $\left(\mathrm{m}^{2} / \mathrm{h}\right), R$ is the steady state recharge that is an estimation of the lateral discharge $(\mathrm{m} / \mathrm{h}), a$ is the upslope drained area per unit contour length $\left(\mathrm{m}^{2} / \mathrm{m}\right)$.

$C, R / T$ and $\phi$ are the calibration parameters of SINMAP and they are introduced as minimum and maximum values, considered uniformly distributed.

According to the combination of the parameters, the values $F S_{\min }$ and $F S_{\max }$ can be obtained; on such a basis, to define the level of stability of the terrain, SINMAP introduces a Stability Index (SI) (fig. 2).

Where $F S_{\min }>1$ the terrain is considered stable and $S I=F S_{\text {min }}$, where $F S_{\text {min }}<1$ there is the possibility of a slope failure and $S I$ is defined as the probability of $F S$ to be greater than $1(\operatorname{Prob}(F S>1))$, where $F S_{\max }<1$, that is $\operatorname{Prob}(F S>1)=0$, the terrain is considered unconditionally unstable.

Arbitrarily, SINMAP considers stable the terrain where SI $>1.5$, moderately stable where $1.5<S I<1.25$ and quasi stable where $1.25<S I<1.0$. Where $1<S I<0.5$ and $0.5<S I<0$, instabilities can occur with different probabilities; the limits $S I=0.5$ and $S I=0.0$ are called lower and upper threshold respectively. Where $S I<0$, Pack et al. [1998] argue that such areas, if not failed in reality, must be held in place by forces that are not accounted for in the model (e.g. outcrops or structures) and called them defended.

For more details about SINMAP see the original papers of Pack [1998; 2005] and papers dealing with SINMAP's application [Meisina 2007; Deb 2009; Terhorst 2009].

\subsection{Incorporating the root cohesion into slope stabili- ty models}

The role of vegetation and of forest in particular, is frequently omitted in slope stability modeling or, at the most, it is evocated as an important stabilizing factor that must be neglected due to the scarcity of data [Montgomery 1994; Dietrich 1998; Meisina 2007].

In some cases the contribution of vegetation is included into the calibration procedure in terms of land use [Pack 1998; Casadei 2003; Huang 2006] or estimated from literature data [Dhakal 2003, 2004; Deb 2009].

Only in few cases the presence of vegetation is explicitly accounted for. In such cases it is considered in terms of additional root cohesion and it is estimated by field tests or by rooted-soil reinforcement models [Wu 1995; Claessens 2007; Kuriakose 2009].

In the present work, we use root cohesion values at the depth of interest, obtained by the implementation of the $\mathrm{Wu}$ and Waldron reinforcement model [Waldron 1977; Wu 1976], carried out by the considered forest species in similar areas [Bischetti 2009].

\subsection{The experimental area}

The area considered in the present study is the catchment of the Inganna creek, which is located 35 $\mathrm{km}$ north of the city of Lecco on Lake Como. The area of the catchment is almost within the municipality of Colico, which developed on the Inganna creek's fan. The catchment area at the section inflowing into Lake Como is $12 \mathrm{~km}^{2}$ and the application of SINMAP has been limited to the non-urban area of the catchment, above $330 \mathrm{~m}$ a.s.1.

The mean elevation of the catchment is $970 \mathrm{~m}$ a.s.l., whereas the maximum elevation is $2160 \mathrm{~m}$ a.s.l. (Mt. Legnone); the mean hillslope steepness is $35^{\circ}$.

The land use is mainly forest and pasture: broadleaf (black locust and sweet chestnut) up to the elevation of $850 \mathrm{~m}$ a.s.l., coniferous (Norway spruce and European larch) for elevations between 850 and 


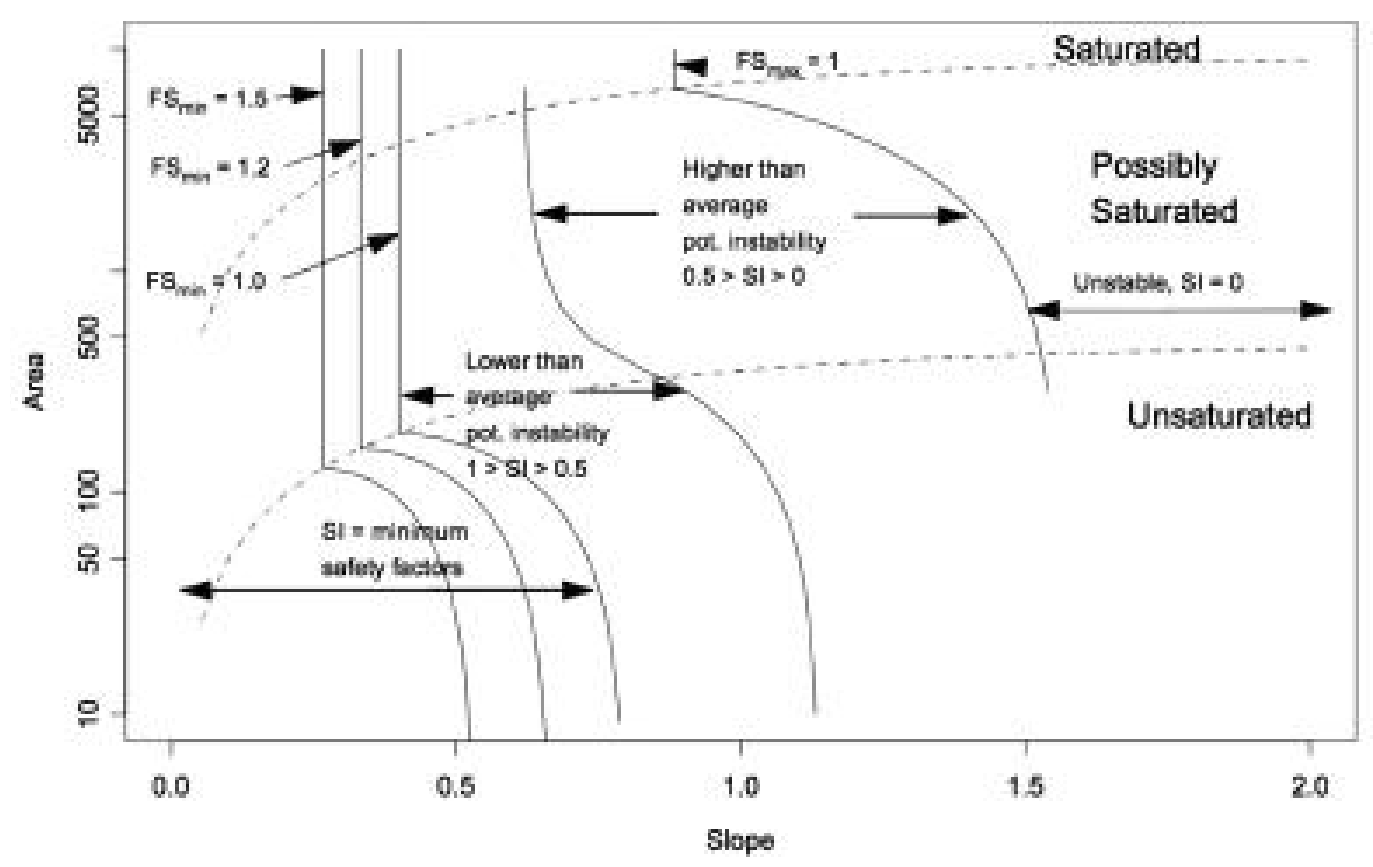

Fig. 2 - Stability Index and stability classification (after Pack [1998])

1130-1450 m a.s.1., according to hillslopes aspects, and pasture or sparse natural grass vegetation at higher elevations.

The lithology is represented mainly by gneiss and mica schist, outcropping or covered by forest cambisol; the remaining area is covered by glacial and eluvial deposits, characterised by regosols.

The Digital Elevation Model has been obtained from elevation points provided by the Territorial Information System of Regione Lombardia, with a regular grid size of $10 \mathrm{~m}$. Such a size can be considered a compromise between the need to describe at best the local steepness [Pack 1998] and the need to avoid a loss of the predictive capability of the adopted hydrologic model due to a too fine spatial resolution [Tarolli 2006].

The data base of occurred landslides, needed for model calibration and validation, has been obtained from the landslide inventory of Regione Lombardia (IFFI) [Ceriani 2005]. Among all the inventoried phe- nomena only those that can be classified as shallow landslides have been extracted and used (53 events).

\subsection{SINMAP calibration}

SINMAP, as mentioned, has been developed under a probabilistic perspective and implicitly it undertakes that the parameters "may be adjusted (and calibrated) for geographic 'calibration regions' based upon soil, vegetation or geologic data." [Pack 2005 p. III].

Calibrating a spatially distributed model is a difficult task, especially on a qualitative basis and without an automatic optimization procedure. In the case of SINMAP the calibration procedure consists in an iterative adjustment of the parameters, based on a visual qualitative assessment of the output with respect to the observed landslides [Pack 2005; Deb 2009].

In order to avoid the level of subjectivity typical of the visual approach, we calibrated SINMAP with reference to three different performance indexes: the

\begin{tabular}{|c|c|c|c|c|}
\hline Region & Vegetation type & Area ${\left(\mathbf{k m}^{2}\right)}^{2}$ & $\begin{array}{c}\mathbf{C}_{\mathbf{r}} \\
(\mathbf{k P a})\end{array}$ & $\begin{array}{c}\text { Depth } \\
(\mathbf{m})\end{array}$ \\
\hline 1 & Sweet chestnut and black locust $^{1}$ & 4.7 & $1.71-8.23$ & $0.5-1.0$ \\
\hline 2 & European beech and birch $^{1}$ & 1.3 & $0.00-18.79$ & $0.5-1.0$ \\
\hline 3 & Silver fir and Norway spruce $^{1}$ & 1.2 & $0.03-5.00$ & $0.5-1.0$ \\
\hline 4 & European larch $^{1}$ & 0.4 & $1.43-16.93$ & $0.5-1.0$ \\
\hline 5 & Pasture and natural sparse grass $^{2}$ & 1.2 & $0.00-10.7$ & $0.3-0.5$ \\
\hline
\end{tabular}

TABLE 1 - calibration regions, vegetation type and related root cohesion values ( ${ }^{1}$ from Bischetti [2009]; ${ }^{2}$ from Preston [1999]). 
widely used Success Rate (SR), the Modified Success Rate of Huang [2006] (MSR) and the herein proposed Weighted Modified Success Rate (WMSR). The range of SINMAP parameters have been iteratively adjusted to obtain the maximum values for each of the target indexes.

The calibration procedure has been carried out for the considered area as a whole (single calibration region - SCR) and for different sub-areas (multiple calibration regions - MCR). For the multiple calibration regions case, five regions have been identified based on vegetation type (tab. 1) and taking care that a minimum of 5 observed landslides fall within each region.

Geotechnical properties have been assumed the same for all regions, due to the small area of the catchment. Soil cohesion has been taken as negligible and soil friction angles ranging between $17^{\circ}$ and $31^{\circ}$, as obtained from shear stress tests by Crosta [2004] for the same area. Soil unit weight has been assumed $20 \mathrm{kN} / \mathrm{m}^{3}$ [Lancellotta 2003] and the soil depth variable according to the vegetation type. Based on literature information and field observation, the sliding depth has been taken to vary between $50 \mathrm{~cm}$ and 100 $\mathrm{cm}$ for forests [Bischetti 2009], whereas between 30 $\mathrm{cm}$ and $50 \mathrm{~cm}$ for grass and sparse vegetation.

Root cohesion values at different depths have been taken from previous work [Bischetti 2005, 2009] and literature; to be conservative only basal root cohesion has been considered (tab. 1).

$T / R$ values for the different regions have been calibrated, since both recharge and transmissivity are difficult to estimate in a spatially distributed manner [Meisina 2007].

\section{Results}

\subsection{Single calibration region approach}

Adopting the Single Calibration Region approach, we obtained the parameter values as reported in table 2 , whereas stability maps are showed in figure 3 .

Using $S R$ as the target index, the calibration procedure leads to obtain that $96.2 \%$ of the observed landslides are located in areas classified as unstable
(18.9\% in the lower threshold, $69.8 \%$ in the upper threshold and $7.5 \%$ in defended). In such a scenario, however, $80.7 \%$ of the considered area is estimated as unstable $(46.9 \%$ lower threshold, $30.7 \%$ upper threshold and $3.1 \%$ defended) and $19.3 \%$ as stable $(11.4 \%$ stable, $3.0 \%$ moderately and $4.9 \%$ quasi-stable stable). MSR results 57.6 and WMRS results 70.5.

Using $M S R$ as the target index, the calibration leads to have that $87.0 \%$ of the observed landslides are located in areas classified as unstable $(43.4 \%$ in the lower threshold, $37.7 \%$ in the upper threshold and $7.5 \%$ in defended). In such a scenario $40.9 \%$ of the considered area is estimated as unstable $(25.2 \%$ lower threshold, $12.6 \%$ upper threshold and $3.1 \%$ defended) and $59.1 \%$ as stable $(31.9 \%$ stable, $11.1 \%$ moderately and $16.0 \%$ quasi-stable stable). MSR results 73.0 and WMRS results 77.7.

The same results have been obtained adopting $W M S R$ as the target index.

\subsection{Multiple Calibration Regions approach}

Adopting the Multiple Calibration Regions approach we obtained the parameter values reported in table 3; stability maps are showed in figure 4.

Using $S R$ as the target index, the calibration leads to obtain that $90.6 \%$ of the observed landslides are located in areas classified as unstable $(47.2 \%$ in the lower threshold, $35.8 \%$ in the upper threshold and $7.5 \%$ in defended). In such a scenario $60.3 \%$ of the considered area is estimated as unstable $(36.8 \%$ lower threshold, $18.1 \%$ upper threshold and $5.4 \%$ defended) and $39.7 \%$ as stable (18.4\% stable, $7.2 \%$ moderately and $14.1 \%$ quasi-stable stable). MSR results 65.5 and WMRS results 74 .

Using $M S R$ as the target index, the calibration leads to obtain that $75 \%$ of the observed landslides are located in areas classified as unstable $(41.5 \%$ in the lower threshold, $24.5 \%$ in the upper threshold and $9.4 \%$ in defended). In such a scenario $25.5 \%$ of the considered area is estimated as unstable $(11.6 \%$ lower threshold, $8.3 \%$ upper threshold and 5.6\% defended) and $74.5 \%$ as stable $(42.9 \%$ stable, $12.7 \%$ moderately and $18.9 \%$ quasi-stable). MSR results 74.6 and WMRS results 76.1 .

Using WMSR as the target index, the calibration

\begin{tabular}{|c|c|c|c|c|c|c|c|c|}
\hline \multirow{2}{*}{$\begin{array}{l}\text { Target } \\
\text { index }\end{array}$} & & stab & unst & $S R$ & $S_{R} / S_{O}$ & $\mathbf{I}_{\mathrm{av}}$ & MSR & WMSR \\
\hline & & $19.3 \%$ & $80.7 \%$ & 96.2 & 19 & 54 & 57.6 & 70.5 \\
\hline \multirow{2}{*}{$S R$} & $C$ & $T / R$ & $\mathbf{S}$ & MS & QS & LT & UT & D \\
\hline & $0.1-0.6$ & $500-1000$ & 11.4 & 3.0 & 4.9 & 46.9 & 30.7 & 3.1 \\
\hline \multirow{4}{*}{ MSR } & & stab & unst & $S R$ & $S_{R} / S_{O}$ & $\mathbf{I}_{\mathrm{av}}$ & $M S R$ & WMSR \\
\hline & & $59.1 \%$ & $40.9 \%$ & 87.0 & 59 & 62 & 73.0 & 77.7 \\
\hline & $C$ & $T / R$ & $\mathbf{S}$ & MS & QS & LT & UT & D \\
\hline & $0.4-0.6$ & $500-1000$ & 31.9 & 11.1 & 16.0 & 25.2 & 12.6 & 3.1 \\
\hline
\end{tabular}

TABLE 2 - calibration parameters and performance indexes for the Single Region Calibration for $S R$ and $M S R$ target $\left(\phi=17^{\circ}-31^{\circ}, \mathrm{S}=\%\right.$ stable, MS=\% moderately stable, $\mathrm{QS}=\%$ quasi-stable, $\mathrm{LT}=\%$ lower threshold, UT=\% upper threshold, $\mathrm{D}=\%$ defended) 


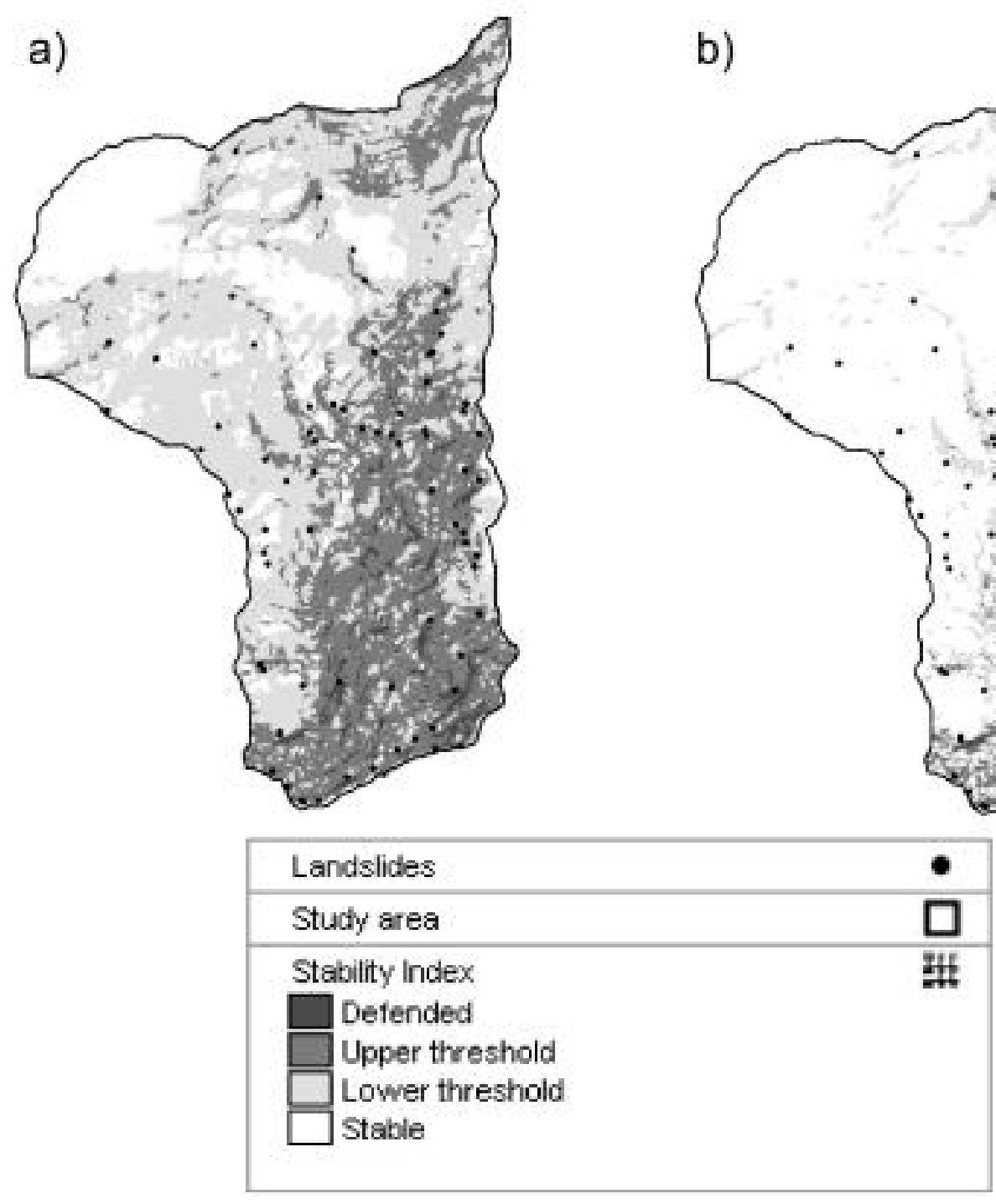

Fig. 3 - Stability Index maps for Single Calibration Region obtained calibrating the parameters with $S R$ (a) and MSR and WMSR (b) as target index (black dots are the observed landslides).

leads to obtain that $79.2 \%$ of the observed landslides are located in areas classified as unstable $37.7 \%$ in the lower threshold, $34.0 \%$ in the upper threshold and $9.4 \%$ in defended). In such a scenario, $30.0 \%$ of the considered area is estimated as unstable $(13.9 \%$ lower threshold, $10.0 \%$ upper threshold and $6.1 \%$ defended) and $70.0 \%$ as stable (38.7\% stable, $12.4 \%$ moderately stable and $19.0 \%$ quasi-stable). MSR results 74.6 and WMRS results 76.1 .

\subsection{Inclusion of root cohesion}

SINMAP has also been run without calibration, using the information related to land use. For each region $C$ has been evaluated based on the range of the likely sliding depth and on the range of root cohesion values at such depth, for those plant species existing in the region. The range values of $\phi$ have been taken from laboratory and field data [Crosta 2004] and the range values of $T / R$ are those already used in the Multiple Calibration Regions procedure.
The parameters and the results are reported in table 4 , whereas the stability map is shown in figure 5 .

$96.2 \%$ of the observed landslides are located in areas classified as unstable $(83.0 \%$ in the lower threshold, $9.4 \%$ in the upper threshold and $3.8 \%$ in defended). In such a scenario $82.7 \%$ of the considered area is estimated as unstable $(68.3 \%$ lower threshold, $12.0 \%$ upper threshold and $2.4 \%$ defended) and $17.3 \%$ as stable $(10.1 \%$ stable, $2.9 \%$ quasi-stable and $4.2 \%$ moderately stable). MSR results 56.6 and WMRS results 69.8 .

The values of $c_{r}$ obtained from the field [Bischetti 2009] and from literature [Preston 1999] at the selected depths have been compared with those extracted from the $C$ values calibrated with the multiple calibration regions approach (tab. 5).

The values of root cohesion derived from calibrated $C$, show a narrower range with respect to those obtained from the field. Moreover, it can be noted that the range of $c_{r}$ values decreases passing from a single calibration to a multiple calibration approach and from $S R$ to $M S R$ and WMSR as the target index. 


\begin{tabular}{|c|c|c|c|c|c|c|c|c|}
\hline \multirow{3}{*}{$S R$ target } & & stab & unst & $S R$ & $S_{R} / S_{O}$ & $\mathbf{I}_{\mathrm{av}}$ & MSR & WMSR \\
\hline & & $39.7 \%$ & $60.3 \%$ & 90.6 & 40 & 58 & 65.3 & 73.7 \\
\hline & $C$ & $T / R$ & $\mathbf{S}$ & MS & QS & LT & UT & D \\
\hline $\begin{array}{l}\text { Sweet chestnut and black } \\
\text { locust }\end{array}$ & $0.15-0.45$ & $500-1000$ & 23.4 & 5.7 & 10.7 & 40.7 & 17.5 & 2.0 \\
\hline $\begin{array}{l}\text { European beech and } \\
\text { birch }\end{array}$ & $0.42-0.47$ & $100-500$ & 17.9 & 14.4 & 20.8 & 29.3 & 15.2 & 2.4 \\
\hline $\begin{array}{l}\text { Silver fir and Norway } \\
\text { spruce }\end{array}$ & $0.38-0.38$ & $300-500$ & 11.9 & 9.0 & 18.6 & 16.8 & 19.0 & 24.6 \\
\hline European larch & $0.40-0.50$ & $500-1000$ & 14.6 & 8.4 & 19.2 & 28.3 & 18.1 & 11.3 \\
\hline $\begin{array}{l}\text { Pasture and natural } \\
\text { sparse grass }\end{array}$ & $0.44-0.50$ & $100-300$ & 6.8 & 3.4 & 14.5 & 52.0 & 22.5 & 0.7 \\
\hline \multirow{3}{*}{$M S R$ target } & & stab & unst & $S R$ & $S_{R} / S_{O}$ & $\mathbf{I}_{\mathrm{av}}$ & $M S R$ & WMSR \\
\hline & & $74.5 \%$ & $25.5 \%$ & 75 & 75 & 62 & 75 & 75 \\
\hline & $C$ & $T / R$ & $\mathbf{S}$ & MS & QS & LT & UT & D \\
\hline $\begin{array}{l}\text { Sweet chestnut and black } \\
\text { locust }\end{array}$ & $0.54-0.57$ & $500-1000$ & 58.6 & 14.3 & 17.0 & 5.4 & 2.9 & 1.9 \\
\hline $\begin{array}{l}\text { European beech and } \\
\text { birch }\end{array}$ & $0.50-0.57$ & $100-500$ & 21.5 & 15.1 & 22.1 & 25.9 & 12.9 & 2.4 \\
\hline $\begin{array}{l}\text { Silver fir and Norway } \\
\text { spruce }\end{array}$ & $0.49-0.55$ & $300-500$ & 13.9 & 9.3 & 21.8 & 23.2 & 20.0 & 11.7 \\
\hline European larch & $0.55-0.56$ & $500-1000$ & 25.4 & 17.2 & 29.0 & 14.1 & 6.7 & 7.5 \\
\hline $\begin{array}{l}\text { Pasture and natural } \\
\text { sparse grass }\end{array}$ & $0.59-0.60$ & $100-300$ & 7.2 & 3.8 & 17.6 & 25.0 & 26.0 & 20.5 \\
\hline \multirow{3}{*}{ WMSR target } & & stab & unst & $S R$ & $S_{R} / S_{O}$ & $\mathbf{I}_{\mathrm{av}}$ & MSR & WMSR \\
\hline & & $70 \%$ & $30 \%$ & 79.2 & 70 & 62 & 74.6 & 76.1 \\
\hline & $C$ & $T / R$ & $\mathbf{S}$ & MS & QS & LT & UT & D \\
\hline $\begin{array}{l}\text { Sweet chestnut and black } \\
\text { locust }\end{array}$ & $0.48-0.52$ & $500-1000$ & 58.6 & 14.3 & 17.0 & 5.4 & 2.9 & 1.9 \\
\hline $\begin{array}{l}\text { European beech and } \\
\text { birch }\end{array}$ & $0.48-0.57$ & $100-500$ & 21.5 & 15.1 & 22.1 & 25.9 & 12.9 & 2.4 \\
\hline $\begin{array}{l}\text { Silver fir and Norway } \\
\text { spruce }\end{array}$ & $0.49-0.55$ & $300-500$ & 13.9 & 9.3 & 21.8 & 23.2 & 20.0 & 11.7 \\
\hline European larch & $0.55-0.56$ & $500-1000$ & 25.4 & 17.2 & 29.0 & 14.1 & 6.7 & 7.5 \\
\hline $\begin{array}{l}\text { Pasture and natural } \\
\text { sparse grass }\end{array}$ & $0.55-0.60$ & $100-300$ & 7.2 & 3.8 & 17.6 & 25.0 & 26.0 & 20.5 \\
\hline
\end{tabular}

TABLE 3 - calibration parameters and performance indexes for the Multiple Calibration Regions for $S R, M S R$ and WMSR target $\left(\phi=17^{\circ}-31^{\circ}, \mathrm{S}=\%\right.$ stable, $\mathrm{MS}=\%$ moderately stable, $\mathrm{QS}=\%$ quasi-stable, $\mathrm{LT}=\%$ lower threshold, $\mathrm{UT}=\%$ upper threshold, $\mathrm{D}=\%$ defended).

\begin{tabular}{|c|c|c|c|c|c|c|c|c|}
\hline \multirow{3}{*}{ Regions } & & stab & unst & $S R$ & $S_{R} / S_{O}$ & $\mathbf{I}_{\mathrm{av}}$ & $M S R$ & WMSR \\
\hline & & $17.3 \%$ & $82.7 \%$ & 96.2 & 17 & 53 & 56.6 & 69.8 \\
\hline & $C$ & $T / R$ & $\mathbf{S}$ & MS & QS & LT & UT & D \\
\hline $\begin{array}{l}\text { Sweet chestnut and black } \\
\text { locust }\end{array}$ & $0.09-0.84$ & $500-1000$ & 17.6 & 5.2 & 7.3 & 62.9 & 6.9 & 0.0 \\
\hline $\begin{array}{l}\text { European beech and } \\
\text { birch }\end{array}$ & $0.00-1.92$ & $100-500$ & 1.6 & 0.1 & 0.3 & 98.0 & 0.0 & 0.0 \\
\hline $\begin{array}{l}\text { Silver fir and Norway } \\
\text { spruce }\end{array}$ & $0.00-0.51$ & $300-500$ & 1.3 & 0.2 & 0.6 & 20.3 & 60.2 & 17.3 \\
\hline European larch & $0.07-1.73$ & $500-1000$ & 2.7 & 1.3 & 2.8 & 93.2 & 0.0 & 0.0 \\
\hline $\begin{array}{l}\text { Pasture and natural } \\
\text { sparse grass }\end{array}$ & $0.00-1.82$ & $100-300$ & 0.9 & 0.1 & 0.2 & 98.9 & 0.0 & 0.0 \\
\hline
\end{tabular}

TABLE 4 - parameters and performance indexes for the no-calibration scenario $\left(\phi=17^{\circ}-31^{\circ}, \mathrm{S}=\%\right.$ stable, MS $=\%$ moderately stable, $\mathrm{QS}=\%$ quasi-stable, $\mathrm{LT}=\%$ lower threshold, $\mathrm{UT}=\%$ upper threshold, $\mathrm{D}=\%$ defended) 

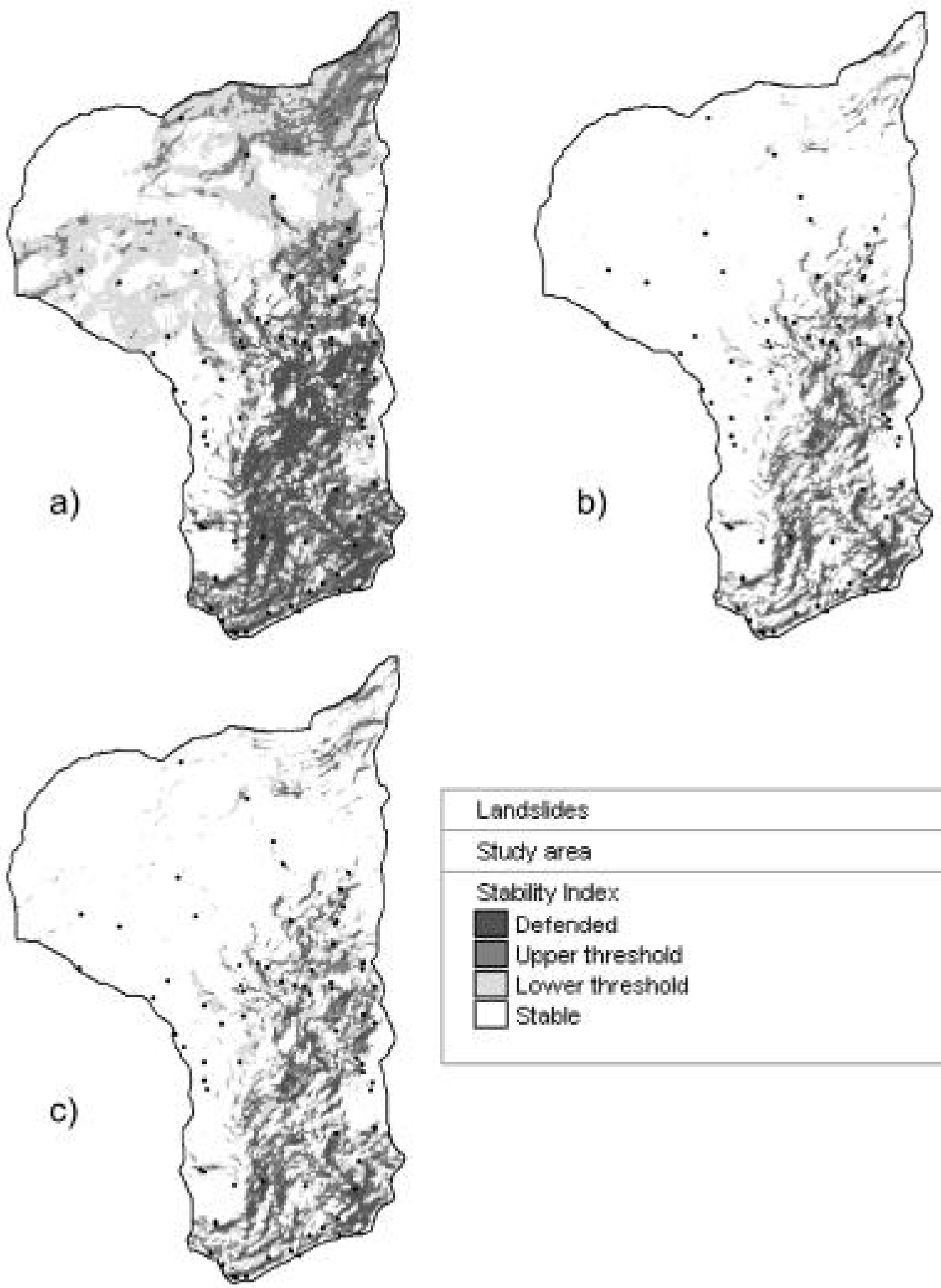

\begin{tabular}{l}
\hline Landslides \\
\hline Study area \\
\hline Stability index \\
\hline Detended \\
Upper threshold \\
\hline Lower threshold \\
Stable
\end{tabular}

Fig. 4 - Stability Index maps for Multiple Calibration Regions obtained calibrating the parameters with $S R$ (a), MSR (b) and $W M S R$ (c) as target index (black dots are the observed landslides)

\section{Discussion and conclusions}

\subsection{Calibration procedure}

The underlying idea in calibrating spatially distributed slope stability models, is that the areas where there are the same conditions of those areas which experienced instabilities, must be simulated as unstable. Sometimes, however, models are not capable to capture the very local factors that are at the base of slope failure (e.g. very local steepness that is not represented by DEM, pore pressure due to soil heterogeneity, uncertainty in geotechnical properties, sliding depth). Attempting to "push" all the observed landslides into low stability areas, then, leads models to evaluate as unstable a great portion of the studied areas, decreasing also their capability to discriminate stable-unstable areas.

To avoid that, some Authors assume that only a minor portion of an area can be really unstable [Casadei 2003] and set an arbitrarily value for the portion of the catchment classified as unstable. Such an approach, however, is subjective and it is not reasonable 


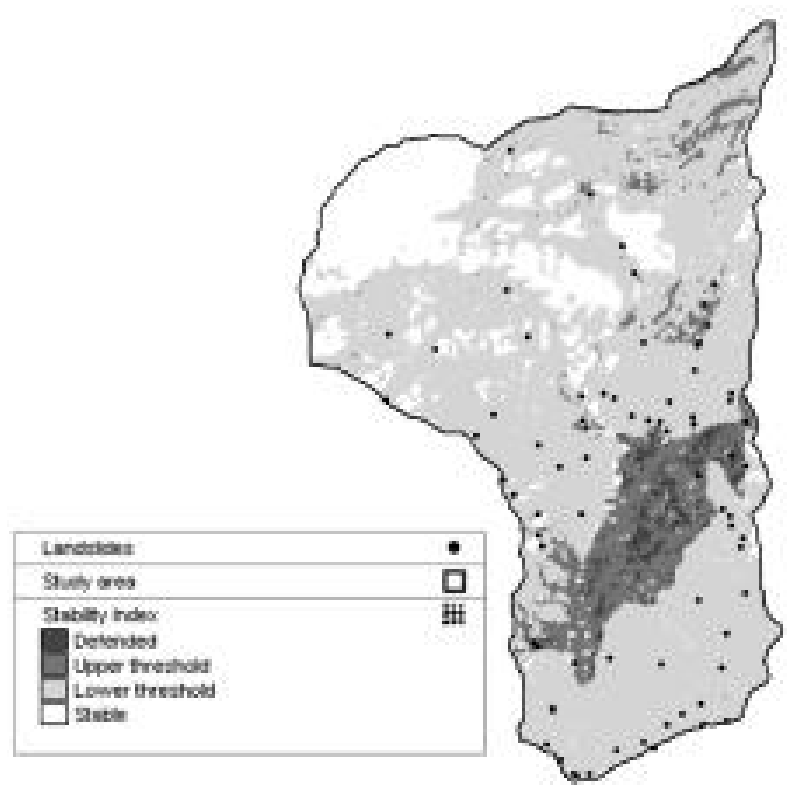

Fig. 5 - Stability Index maps for Multiple Calibration Regions obtained assuming $c_{r}$ and depth values (black dots are the observed landslides) in small steep catchments, where most of the area stands in a situation that is intrinsically prone to be unstable due to steepness and/or to mechanical soil properties. In the present case, for example, the observed landslides spread over the whole Contributing Area-Slope diagram (fig. 6), which in SINMAP is used for calibration. Any attempt to increase the capability of the model to simulate as unstable the locations where landslides have occurred, then, inevitably leads to simulate all those cells with similar conditions as unstable.

The results obtained in the present work confirm such consideration and clearly show how the use of $S R$ as target index tends to over-predict the extension of unstable areas. Using $S R$ as target index, in fact, most of the considered catchment is simulated as unstable, whereas the observed landsides and, above all, the field survey show the contrary.

The assessment of stability models efficiency, then, cannot be based only on the observed instabilities in unstable areas, but must consider also the rate of correctly evaluated stable areas. In the present work, the

\begin{tabular}{|c|c|c|c|c|c|c|}
\hline & \multirow{2}{*}{$\begin{array}{c}\mathbf{D}_{\min } \\
(\mathbf{m})\end{array}$} & \multirow{2}{*}{$\begin{array}{c}\mathbf{D}_{\max } \\
(\mathbf{m})\end{array}$} & \multicolumn{2}{|c|}{$\begin{array}{c}\text { Estimated } c_{\mathrm{r}} \\
(\mathrm{kPa})\end{array}$} & \multicolumn{2}{|c|}{$\begin{array}{c}\text { Observed } c_{\mathrm{r}} \\
(\mathrm{kPa})\end{array}$} \\
\hline & & & Min & $\max$ & $\min$ & $\max$ \\
\hline \multicolumn{7}{|c|}{ Success Rate as target index } \\
\hline$S C R$ & 0.3 & 1.0 & 0.6 & 10.2 & 0.00 & 18.79 \\
\hline \multicolumn{7}{|l|}{$M C R$} \\
\hline Sweet chestnut and black locust & 0.5 & 1.0 & 1.4 & 8.8 & 1.71 & 8.23 \\
\hline European beech and birch & 0.5 & 1.0 & 4.3 & 11.1 & 0.00 & 18.79 \\
\hline Silver fir and Norway spruce & 0.5 & 1.0 & 4.4 & 9.2 & 0.03 & 5.00 \\
\hline European $\operatorname{larch}^{1}$ & 0.5 & 1.0 & 3.8 & 9.8 & 1.43 & 16.93 \\
\hline Pasture and natural sparse grass & 0.3 & 0.5 & 3.1 & 7.8 & 0.00 & 10.70 \\
\hline \multicolumn{7}{|c|}{ Modified Success Rate as target index } \\
\hline$S C R$ & 0.3 & 1.0 & 2.3 & 4.7 & 0.00 & 18.79 \\
\hline \multicolumn{7}{|l|}{$M C R$} \\
\hline Sweet chestnut and black locust & 0.3 & 1.0 & 3.1 & 3.4 & 1.71 & 8.23 \\
\hline European beech and birch & 0.3 & 1.0 & 2.9 & 3.7 & 0.00 & 18.79 \\
\hline Silver fir and Norway spruce & 0.3 & 1.0 & 2.8 & 3.6 & 0.03 & 5.00 \\
\hline European $\operatorname{larch}^{1}$ & 0.3 & 1.0 & 3.2 & 3.3 & 1.43 & 16.93 \\
\hline Pasture and natural sparse grass & 0.3 & 1.0 & 3.4 & 3.3 & 0.00 & 10.70 \\
\hline \multicolumn{7}{|c|}{ Weighted Modified Success Rate as target index } \\
\hline$S C R$ & 0.3 & 1.0 & 2.3 & 4.7 & 0.00 & 18.79 \\
\hline \multicolumn{7}{|l|}{$M C R$} \\
\hline Sweet chestnut and black locust & 0.3 & 1.0 & 2.8 & 3.5 & 1.71 & 8.23 \\
\hline European beech and birch & 0.3 & 1.0 & 2.8 & 3.8 & 0.00 & 18.79 \\
\hline Silver fir and Norway spruce & 0.3 & 1.0 & 2.8 & 3.6 & 0.03 & 5.00 \\
\hline European $\operatorname{larch}^{1}$ & 0.3 & 1.0 & 3.2 & 3.3 & 1.43 & 16.93 \\
\hline Pasture and natural sparse grass & 0.3 & 1.0 & 3.2 & 3.5 & 0.00 & 10.70 \\
\hline
\end{tabular}

TABLE 5 - Values of root cohesion calculated from calibrated $C$ values and from previous work and literature 


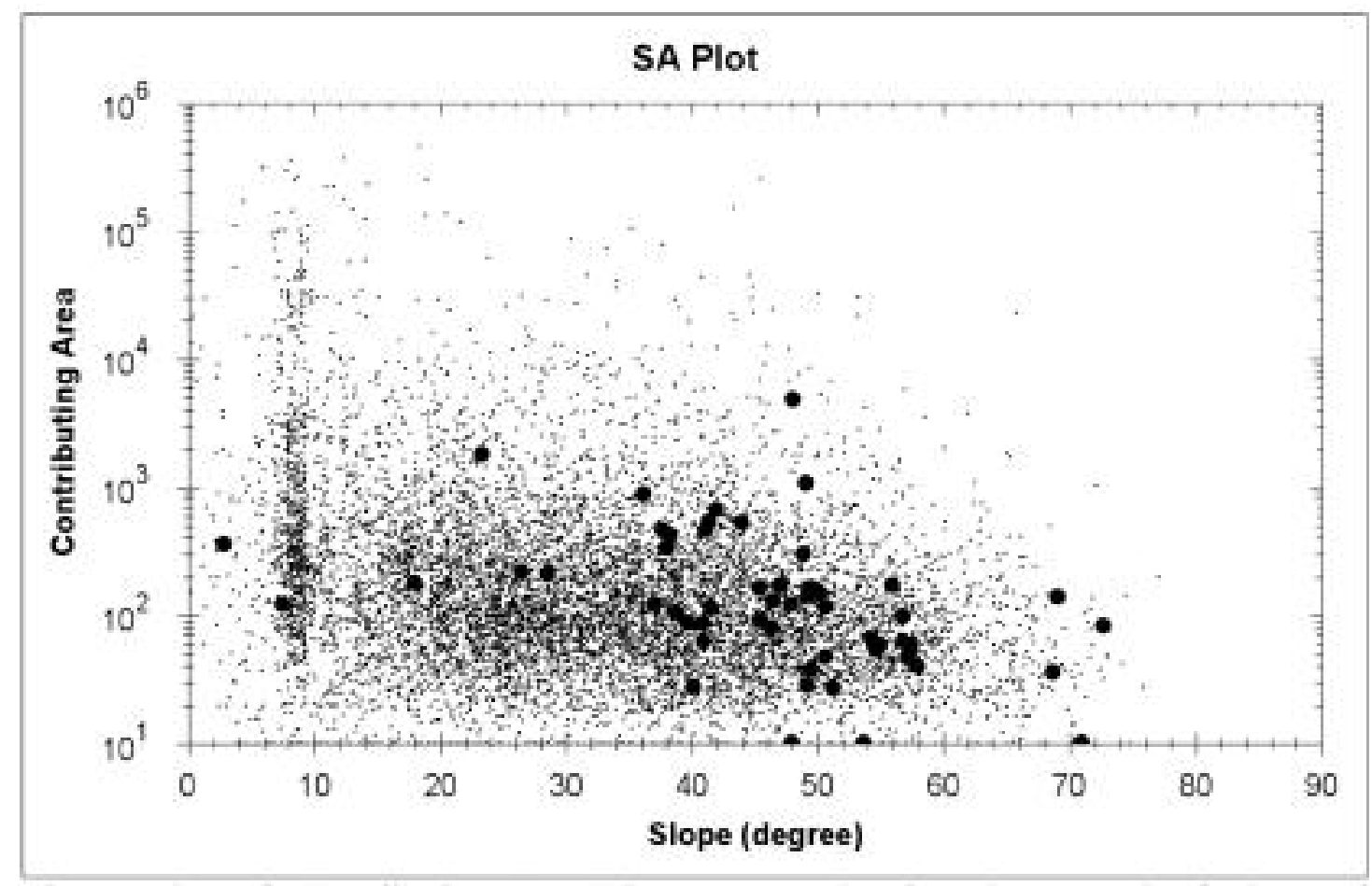

Fig. 6 - Plot of Contributing Area-Slope space showing the spread of observed landslides

use of MSR and WMSR seems to allow a better discrimination between stable and unstable areas, representing a promising approach for assessing the validity and comparing the results of slope stability models, as already proposed by Huang [2006] and Rosso [2006].

The weakness of $S R$ in assessing the efficiency of SINMAP is particularly evident when the Single Calibration Region approach is adopted. In this case, in fact, since the range of parameter values must be unique for the whole area, it must be wide enough to cover all the different conditions; therefore, unless the area is really homogeneous, the effect of the lower limit of the range will extend over the entire area. This problem may be overcome by the multiple calibration regions approach, where the considered area is split into sub-regions and a specific range of parameter values can be defined for each region, limiting the effect of low values of parameters only to those areas where it is appropriate.

When enough calibration data are available, then, such an approach should be preferred. Since vegetation can partially represent the variability of factors involved in slope stability (root cohesion, depth and, partially, hydrologic soil properties) and vegetation maps are generally available, such information should be used to implement the multiple regions approach.

The difference between the single region and multiple regions approach is not so clear when MSR or $W M S R$ are adopted as target index. In the first case there is no difference and in the second it is very small. In principle, WMSR is more conservative with respect to $M S R$ due to the greater weight given to the right identification of observed landslides, but more investigations in different areas could give more indications.

\subsection{Use of root cohesion values}

A sensitivity analysis confirms that $C$ is the most significant parameter, whereas $\phi$ plays a minor role as already suggested by Morrissey [2001] and Deb [2009]. Any improvement on sliding depth and root cohesion, as a consequence, are of particular relevance.

In terms of root cohesion values, the calibration carried out for the considered area seems to constrain its values into a narrower range with respect to those observed in the field (tab. 5). Such a behavior could be due to the fact that the instability phenomena occurred up to now have not explored the whole range of root cohesion variability or, more likely, that the SINMAP assumption of uniform probability distribution of $C$ values does not hold. In the case of uniform distribution, in fact, all the values have the same weight and the extreme values must be excluded to obtain the best fitting between observed and simulated stable-unstable cells. Introducing a more realistic distribution of probability of the root cohesion and of the sliding depth (e.g. normal, triangular, lognormal, etc.), such shortcomings should be overcome. Such an objective represents the perspective for future work.

\subsection{Classification of unstable areas}

As already mentioned in small and steep catchments a large portion of the considered area is intrinsically prone to instability, as in the present case, and 


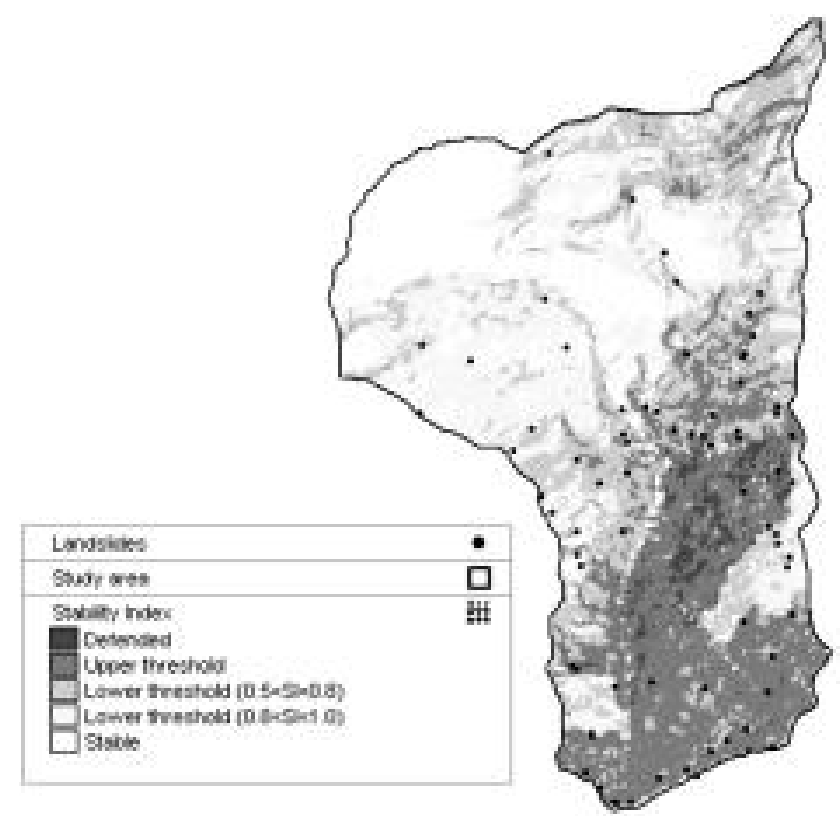

Fig. 7 - Stability Index maps for Multiple Calibration Regions obtained imposing $c_{r}$ and depth values with the new class for low probability of failure (black dots are the observed landslides)

is estimated as unstable. Most of such unstable areas, however, stands between the lower and the upper threshold $(1<\operatorname{Prob}(\mathrm{FS}>1)<0.5)$, indicating that there is a potential instability but with a minor probability of occurrence. The possibility to discriminate the areas potentially unstable in more than two classes, then, could be very useful.

To test the relevance of such an option, a new class for unstable terrain has been introduced; all cells with $1<\operatorname{Prob}(\mathrm{FS}>1)<0.8$ have been assigned to a new class with a low probability of failure (quasi-unstable, according to SINMAP classification of stable cells).

The stability map obtained in this way for the case of no-calibration and multiple areas is showed in figure 7. It can be noted that most of the observed landslides do not fall in the new class, characterised from a low chance of failure. The performance indexes with a new (arbitrary) critical threshold for $S I<0.8$ are: $S R=85 \%, M S R=67.5$ and $W M S R=73.3$. Such an approach can be particularly useful in terms of hazard mapping.

\section{Acknowledgments}

The Authors gratefully acknowledge prof. Claudio Gandolfi for reviewing the manuscript and for providing useful advice.

\section{References}

Beven K.J., Kirkby M.J., A Physically Based Variable Contributing Area Model of Basin Hydrology. Hydrol. Sci. Bull., 1979, 24(1), 43-69.

Bischetti G.B., Chiaradia E.A., Simonato T. et al., Root strength and root area ratio of forest species in Lombardy (Northern Italy). Plant and Soil, 2005, 278, 11-22.

Bischetti G.B., Chiaradia E.A., Epis T., Morlotti M., Root cohesion of forest species in the Italian Alps. Plant and Soil, 2009, 324(1), 71-89.

Borga M., Fontana G.D., Cazorzi F., Analysis of topographic and climatic control on rainfall-triggered shallow landsliding using a quasi-dynamic wetness index. J. Hydrol., 2002, 268(1-4), 56-71.

Calcaterra D., De Riso R., Di Martire D., Assessing shallow debris slide hazard in the Agnano Plain (Naples, Italy) using SINMAP, a physically based slope-stability model. In: Lacerda WA, Ehrlich ME, Fontoura SAB, Sayao ASF (Eds.), Taylor and Francis Group, London, 2004, 177-183. vol. 1.

Carrara A., Cardinali M., Guzzetti F., Reichenbach P., GIS technology in mapping landslide hazard in Geographical Information Systems. In: Assessing Natural Hazards, Carrara A, Guzzetti F (eds). Kluwer, 1995, The Netherlands, 135-175.

Casadei M., Dietrich W.E., Miller N.L., Testing a model for predicting the timing and location of shallow landslide initiation in soil-mantled landscapes. Earth Surf. Proc. Landforms, 2003, 28(9), 925-950.

Ceriani M., Inventario dei Fenomeni Franosi in Lombardia Regione Lombardia. D.G. Protezione civile, Programma delle Ricerche Strategiche, 2005, Milan (in Italian).

Chiaradia E.A., Vegetazione e frane superficiali: applicazione di un modello spazialmente distribuito. Proceedings of the "IX Conv. Naz. AIIA" Ischia Porto, 12-16 settembre 2009 (in Italian).

Claessens L., Heuvelink G.B.M., Schoorl J.M., Veldkamp A., DEM resolution effects on shallow landslide hazard and soil redistribution modelling. Earth Surf. Proc. Landforms, 2005, 30(4), 461-477.

Claessens L., Schoorl J.M., Veldkamp A., Modelling the location of shallow landslides and their effects on landscape dynamics in large watersheds: An application for Northern New Zealand. Geomorph., 2007, 87, 16-27.

Crosta G., Ambrosi C., Agliardi F., Frattini P. et al., Studio geologico, geotecnico, geomeccanico e di pericolosità del versante fronte lago comprendente i comuni di Colico, Dervio, Dorio e Bellano. Regione Lombardia, 2004, Milan (in Italian).

Deb S.K., El-Kadi A.I., Susceptibility assessment of shallow landslides on Oahu, Hawaii, under extreme-rainfall events. Geomorp., 2009, 108, 219-233.

Dhakal A.S., Sidle R.C., Long-term modelling of landslides for different forest management practices. Earth Surf. Proc. Landforms, 2003, 28(8), 853-868.

Dhakal A.S., Sidle R.C., Distributed simulations of landslides for different rainfall conditions. Hydrol. Proc., 2004, 18(4), 757-776.

Dietrich W.E., Montgomery D.R., SHALSTAB: A digital terrain model for mapping shallow landslide potential, http: //socrates.berkeley.edu/<geomorph/shalstab, 1998.

Dietrich W.E., Wilson C.J., Montgomery D.R., McKean J. Analysis of erosion thresholds, channel networks and landscape morphology using a digital terrain model. J. Geol., 1993, 101, 161-180.

Dietrich W.E., McKean J., Bellugi D., Perron T., The prediction of shallow landslide location and size using a multidimensional landslide analysis in a digital terrain model. 
In: Chen C.L., Major J.J. (eds) Proc. Fourth Int. Conf. on Debris-Flow Hazards Mitigation: Mechanics, Prediction, and Assessment (DFHM-4), 2007, Chengdu, China, Sept. 10-13, 2007. The Netherlands, Amsterdam: IOS Press. 12 pp.

Duan J., Grant G.E., Shallow landslide delineation for steep forest watersheds based on topographic attributes and probability analysis. In: Wilson JP, Gallant JC (Eds.), Terrain Analysis: Principles and Applications, 2000, Wiley \& Sons, New York, 311-329.

Guzzetti F., Carrara A., Cardinali M., Reichenbach P., Landslide hazard evaluation: a review of current techniques and their application in a multi-scale study, Central Italy. Geomorph., 1999, 31, 181-216.

Hammond C.D., Hall D., Miller S., Swetik P., Level I Stability Analysis (LISA): Documentation for version 2.0. 1992, Ogden, UT, USA, USDA, Forest Service, Intermountain Research Station GTR No. 285.

Huang J.C., Kao S.J., Hsu M.L., Lin J.C., Stochastic procedure to extract and to integrate landslide susceptibility maps: an example of mountainous watershed in Taiwan. Nat. Hazards Earth Syst. Sc., 2006, 6, 803-815.

Kuriakose Sekhar L., van Beek L.P.H., van Westen C.J., Parameterizing a physically based shallow landslide model in a data poor region. Earth Surf. Proc. Landforms, 2009, 34(6), 867-881.

Lan H., Zhou C., Wang L., Zhang H., Li R., Landslide hazard spatial analysis and prediction using GIS in the Xiaojiang watershed, Yunnan, China. Eng. Geol., 2004, 78(1-2), 109-128.

Lancellotta R., Geotecnica, 1993, Zanichelli, 496 pp. $3^{\text {a }}$ ed.

Meisina C., Scarabelli S., A comparative analysis of terrain stability models for predicting shallow landslides in colluvial soils. Geomorph., 2007, 87(3), 207-223.

Montgomery D.R., Dietrich W.E., A physically based model for the topographic control on the shallow landsliding. Water Resour. Res., 1994, 30, 1153-1171.

Montgomery D.R., Sullivan K., Greenberg H.M., Regional test of a model for shallow landsliding. Hydrol. Proc., 1998, 12(6), 943-955.

Morrissey M.M., Wieczorek G.F., Morgan B.A., A comparative analysis of hazard models for predicting debris flows in Madison County, Virginia. OFR 01-0067. 2001, U.S.G.S.

Pack R.T., Tarboton D.G., Goodwin C.N., The Sinmap Approach to Terrain Stability Mapping. Proc. 8th Congress Int Ass Eng Geol, 1998, Vancouver, British Columbia.

Pack R.T., Tarboton D.G., Goodwin C.N., Prasad A., "SINMAP 2. A Stability Index Approach to Terrain Stability Hazard Mapping, technical description and users guide for version 2.0," 2005, Utah State University.

Preston N.J., Crozier M.J., Resistance to shallow landslide failure through root-derived cohesion in east coast hill country soils, North Island, New Zealand. Earth Surf. Proc. Landforms, 1999, 24, 665-675.

Santini M., Grimaldi S., Nardi F., Petroselli A., Pre-processing algorithms and landslide modelling on remotely sensed DEMs. Geomorph., 2009, 113, 110-125.

Sidle R.C., Pearce A.J., O'Loughlin C.L., Hillslope stability and land use. AGU Water Resources Monograph, 11, 1985, Washington D.C., USA.

Rosso R., Rulli M.C., Vannucchi G., A physically based model for the hydrologic control on shallow landsliding.
Water Resour. Res., 42, W06410, doi:10.1029/ 2005WR004369.

Simoni S., Zanotti F., Bertoldi G., Rigon R. Modelling the probability of occurrence of shallow landslides and channelized debris flows using GEOtop-FS. Hydrol. Proc., 2008, 22(4), 532-545.

Tarolli P., Tarboton D.G., A new method for determination of most likely landslide initiation points and the evaluation of digital terrain model scale in terrain stability mapping. Hydrol. Earth Syst. Sci., 10, 663-677, 2006.

Talebi A., Troch P.A., Uijlenhoet R., A steady-state analytical slope stability model for complex hillslopes. Hydrol. Proc., 2008, 22, 546-553.

Terhorst B., Kreja R., Slope stability modelling with SINMAP in a settlement area of the Swabian Alb. Landslides, 2009, DOI 10.1007/s10346-009-0167-2.

Van Beek H., Assessment of the influence of changes in land use and climate on landslide activity in a Mediterranean environment. $\mathrm{PhD}$ thesis, Utrecht University, 2002, http://igitur-archive.library.uu.nl/dissertations/ 2003-0205-095231/inhoud.htm.

Waldron L.J., The shear resistance of root-permeated homogeneous and stratified soil. 1977, Soil Sci Soc Am J, 41, 843-849.

Wu T.H., Investigation on landslides on Prince of Wales Island. 1976, Alaska Geotech. Rpt No 5 Dpt Civ Eng Ohio State Univ Columbus, USA

Wu W., Sidle R.C., A distributed slope stability model for steep forested basins. Water Res. Res., 1995, 31, 2097 2110.

Zaitchik B.F., van Es H.M., Applying a GIS slope-stability model to site-specific landslide prevention in Honduras. J. Soil Water Cons., 2003, 58, 45-53.

\section{SUMMARY}

In mountainous-forested soil mantled landscapes all around the world, rainfall-induced shallow landslides are one of the most common hydro-geomorphic hazards, which frequently impact the environment and human lives and properties.

In order to produce shallow landslide susceptibility maps, several models have been proposed in the last decade, combining simplified steady state topography-based hydrological models with the infinite slope scheme, in a GIS framework.

In the present paper, two of the still open issues are investigated: the assessment of the validity of slope stability models and the inclusion of root cohesion values.

In such a perspective the "Stability INdex MAPping" has been applied to a small forested pre-Alpine catchment, adopting different calibrating approaches and target indexes. The Single and the Multiple Calibration Regions modality and three quantitative target indexes - the common Success Rate $(S R)$, the Modified Success Rate $(M S R)$, and a Weighted Modified Success Rate (WMSR) herein introduced - are considered.

The results obtained show that the target index can 
significantly affect the values of a model's parameters and lead to different proportions of stable/unstable areas, both for the Single and the Multiple Calibration Regions approach. The use of $S R$ as the target index leads to an over-prediction of the unstable areas, whereas the use of $M S R$ and WMSR, seems to allow a better discrimination between stable and unstable areas.

The Multiple Calibration Regions approach should be preferred, using information on space distribution of vegetation to define the Regions.

The use of field-based estimation of root cohesion and sliding depth allows the implementation of slope stability models (SINMAP in our case) also without the data needed for calibration. To maximize the inclusion of such parameters into SINMAP, however, the assumption of a uniform distribution of probability of the parameters must be overtaken.

In small and steep catchments where there is an intrinsic susceptibility to instability phenomena, moreover, an additional class of low probability of instability $(0.8<\mathrm{P}(\mathrm{FS}>1)<1.0)$ has been proposed to better discriminate the areas classified as unstable.

Keywords: Slope stability modelling, SINMAP, root cohesion.

\section{List of symbols}

$\begin{array}{ll}\beta & \text { slope angle }\left(^{\circ}\right) \\ \phi & \text { internal friction angle }\left(^{\circ}\right) \\ \gamma_{s} & \text { soil unit weight }\left(\mathrm{kN} / \mathrm{m}^{3}\right) \\ \gamma_{w} & \text { water unit weight }\left(\mathrm{kN} / \mathrm{m}^{3}\right) \\ a & \text { upslope drained area per unit contour } \\ & \text { length }\left(\mathrm{m}^{2} / \mathrm{m}\right)\end{array}$

$c_{s} \quad$ soil cohesion $(\mathrm{kPa})$,

$c_{r} \quad$ additional root cohesion $(\mathrm{kPa})$

$r=\frac{\gamma_{e}}{\gamma_{4}} \quad$ water to soil unit weight ratio (-)

$w=\frac{D}{D}=\frac{h_{v}}{h}$ relative wetness (-)

$C=\frac{c_{f}+c_{f}}{h \gamma_{s}}$ combined dimensionless cohesion relative to perpendicular soil thickness (-)

D $\quad$ vertical soil depth (m)

$D_{w} \quad$ vertical water depth (m)

FS Factor of Safety (-)

MSR Modified Success Rate (-)

$N U_{R} \quad$ number of observed landslides actually occurred in predicted unstable areas (\#)

$N U_{O} \quad$ total number of observed landslides (\#)

$R \quad$ steady state recharge that is an estimation of the lateral discharge $(\mathrm{m} / \mathrm{h})$

SI Stability Index (-)

SR Success Rate (-)

$S_{R} \quad$ successfully predicted/ rightly simulated stable cells (\#)

$S_{O} \quad$ total number actual/observed stable cells (\#)

$S_{C} \quad$ simulated stable cells (\#)

$U_{C} \quad$ simulated unstable cells (\#)

$U_{R} \quad$ rightly simulated unstable cells (\#)

$U_{O} \quad$ observed unstable cells (\#)

$T \quad$ transmissivity $\left(\mathrm{m}^{2} / \mathrm{h}\right)$

WMSR Weighted Modified Success Rate (-) 
003_Bischetti(569)_23 1-12-2010 9:48 Pagina 36

$\varnothing$ 